\title{
Explosive Propagation of Aeolosoma Hemprichi in an Activated Sludge-Biofilm Reactor
}

\author{
Yong Zhan', Qingqing Feng', Haidong Zhou ${ }^{1 *}$, Qiang Zhang', Bin Dong ${ }^{2}$ \\ 'School of Environment and Architecture, University of Shanghai for Science and Technology, China \\ ${ }^{2}$ School of Environmental Science, Tongji University, China
}

Received: 5 June 2014

Accepted: 8 July 2014

\begin{abstract}
In order to understand the impact of the explosive propagation of aeolosoma hemprichi on the performance of an activated sludge-biofilm reactor at various temperature conditions, we conducted a beaker experiment and simulated the activated sludge-biofilm reactor, which is operated in a $1.0 \mathrm{~L}$ reactor with the filler dosing rate of $30 \%$ at $20^{\circ} \mathrm{C}, 25^{\circ} \mathrm{C}$, and $30^{\circ} \mathrm{C}$. We inoculate aeolosoma hemprichi after the activated sludgebiofilm reactor became steady, investigated whether and when the explosive propagation of aeolosoma hemprichi occurs at various ambient temperatures, and examined its impact on the performance of the activated sludge-biofilm reactor. The results show that the removal rate of ammonia nitrogen is basically stable at between $90-95 \%$, and that of total nitrogen has remained at around $45 \%$ at $20^{\circ} \mathrm{C}$. When the filler dosage rate is $30 \%$, the removal rate of COD is stable between $85 \%-90 \%$. The population density of aeolosoma hemprichi basically kept at $10 \mathrm{ind} . / \mathrm{mL}$, indicating that the aeolosoma hemprichi did not produce explosive reproduction. The explosive propagation of aeolosoma hemprichi occurs at the temperature of both $25^{\circ} \mathrm{C}$ and $30^{\circ} \mathrm{C}$, while the maximum population densities of aeolosoma hemprichi are $383 \mathrm{ind} . / \mathrm{mL}$ and $200 \mathrm{ind} . / \mathrm{mL}$, respectively. In addition, the explosive propagation has no impact on the removal rates of inlet and outlet COD and $\mathrm{NH}_{3}-\mathrm{N}$, but it leads to an increase in the release rate of TN. Moreover, it is certified that the explosive propagation of aeolosoma hemprichi does not have an impact on the loss of biofilm. Finally, after multivariate regression analysis with SPSS, we concluded that the maximum population density of aeolosoma hemprichi has a significant correlation with the release rate of TN.
\end{abstract}

Keywords: activated sludge-biofilm reactor, aeolosoma hemprichi, population density, ambient temperature, release of nutrients

\section{Introduction}

A hybrid activated sludge-biofilm process has received considerable attention in recent years for the treatment of municipal wastewater [1-5]. An activated sludge-biofilm reactor could be formed by adding the biological carrier into an original aeration tank without reconstructing the reaction pool. Applying the activated sludge-biofilm reactor enables significantly increasing the system biomass and reducing

*e-mail: zhouhaidong@usst.edu.cn system load. The method is suitable for those plants that have no land to expand to treat wastewater [6]. However, the activated sludge-biofilm reactor often generates metazoan in the biological carrier and causes their explosive propagation, which significantly makes deteriorates water quality and undermines the stability of the water system. Aeolosoma hemprichi is the biggest metazoan seen in the activated sludge-biofilm reactor [7-9]. One of the main research topics in the activated sludge-biofilm reactor is to study the impact of aeolosoma hemprichi on the reduction of sludge [5, 10-17]. 
Some scholars have stated that aeolosoma hemprichi uses sludge as food while it releases nutrients, including ammonia nitrogen $\left(\mathrm{NH}_{3}-\mathrm{N}\right)$, total nitrogen $(\mathrm{TN})$, and soluble chemical oxygen demand (COD) [18-22], and have studied the impact of the inoculated tubificidae on the reduction of sludge [23]. In the controlled trials, one group inoculated tubificidae and the other did not. The result shows that sludge reduction in the inoculated group is three times greater than that in the non-inoculated group. In addition, the removal rate of COD increases by $8.7 \%$. They concluded that the tubificidae worms are scavengers and eat organisms in the sludge. In this way, the removal rate of COD is reduced. But the removal rate of ammonia nitrogen is relatively high in the inoculated group. Moreover, the biofilm quantity is up to $6,889 \mathrm{mg} / \mathrm{L}$ in the non-inoculated group, it is only $4,356 \mathrm{mg} / \mathrm{L}$ in the inoculated group. That is mainly because of the tubificidae feeding and the release of metabolites [24, 25]. Wang et al. [26] believed that aeolosoma hemprichi selectively ate ammonia-oxidizing bacteria, which were mostly attached to the suspended filler in the reactor. They further concluded that aeolosoma hemprichi ate a large amount of ammonia oxidizing bacteria in the biofilm so that nitrification was reduced and the concentration of ammonia nitrogen increased.

However, how does the population density of aeolosoma hemprichi affect the operation of the activated sludgebiofilm reactor? What are the indicators to evaluate the performance of the activated sludge-biofilm reactor after the explosive propagation of aeolosoma hemprichi? This paper aims to answer these questions through conducting a beaker experiment and simulating the activated sludge-biofilm reactor. In the study, we first design the experimental indicators. Under different temperature conditions we collect data affecting the activated sludge-biofilm reactor, and analyze the impact of the explosive propagation of aeolosoma hemprichi on its performance.

\section{Experimental}

\section{Devices and Materials}

Devices: XTZ-D microscope, 10 100 $\mu$ Leppendorf Finnpipette, culture vessel with a diameter of $5 \mathrm{~cm}$, analytical balance, ultraviolet spectrophotometer, shaker. MET-
TLER pH, 25 mL colorimetric tube, TGL18-M centrifuge, vacuum pump, acetate fiber filter, filter, tissue grinder.

Materials: glucose, sucrose, ammonium bicarbonate, sodium bicarbonate, peptone, magnesium carbonate powder, $90 \%$ acetone, potassium dihydrogen phosphate.

\section{Experimental Methods}

COD is measured using the potassium dichromate method. $\mathrm{NH}_{3}-\mathrm{N}$ is measured by Nessler's reagent spectrophotometry, and $\mathrm{TN}$ is measured by potassium persulfate oxidation-ultraviolet spectrophotometry. The population density of aeolosoma hemprichi is measured by the crossmarking method. The light incubator for culture. The light intensity and temperature by light incubator to control, $\mathrm{pH}$ adjusted by the $\mathrm{NaOH}$ and $\mathrm{HCl}$ solution. With an optical microscope for measurement we calculated the average amount. The concentration of sludge and biological membrane quantity were measured using the method specified by the Chinese State Environmental Protection Administration in 2002 [27].

\section{Experimental Parameters}

In the study we select the following indicators to evaluate the performance of the activated sludge-biofilm reactor, including temperature, the maximum population density of aeolosoma hemprichi, the removal rate of $\mathrm{COD}$, the removal rate of $\mathrm{NH}_{3}-\mathrm{N}$, and total nitrogen ratio of inlet water to outlet water. The maximum population density of aeolosoma hemprichi refers to the largest population density of aeolosoma hemprichi during the explosive propagation of aeolosoma hemprichi under various temperature gradients. Fig. 1 shows the observed aeolosoma hemprichi and other Oligochaetes in the activated sludge-biofilm reactor druing the experimental period. The removal rate of COD refers to the average removal rate of COD during the operation of the activated sludge-biofilm reactor. The removal rate of $\mathrm{NH}_{3}-\mathrm{N}$ refers to the average removal rate of $\mathrm{NH}_{3}-\mathrm{N}$ during the operation of the activated sludge-biofilm reactor. And the total nitrogen ratio of inlet water to outlet water refers to the ratio of total nitrogen in outlet water to total nitrogen in inlet water during the release of $\mathrm{TN}$ when the explosive propagation of aeolosoma hemprichi occurs.

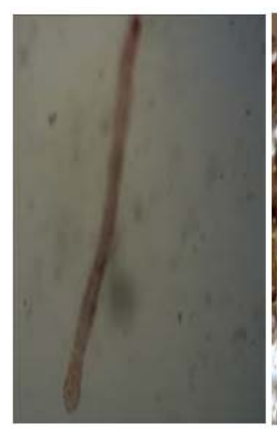

(a)

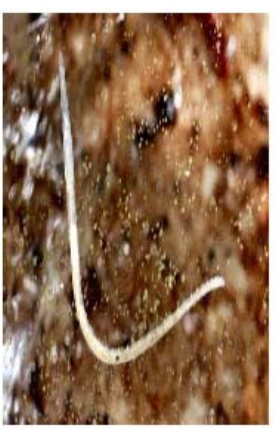

(b)

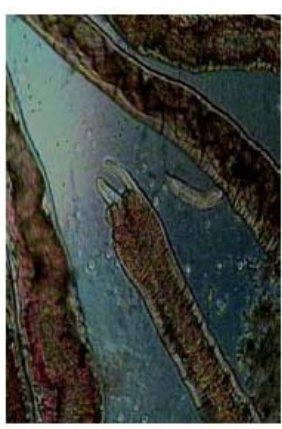

(c)

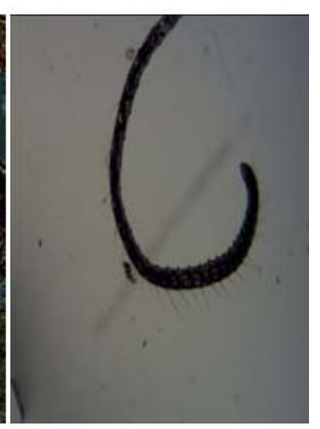

(d)

Fig. 1. Microscope photos of Oligochaetes observed in the activated sludge-biofilm reactor a) Aeolosoma hemprichi, b) Naididae, c) Okiwa sa, and d) Tubificid worms. 


\section{Results and Discussion}

Impact of the Explosive Propagation of Aeolosoma Hemprichi on Removal Rates of $\mathrm{COD}$ and $\mathrm{NH}_{3}-\mathrm{N}$ at $25^{\circ} \mathrm{C}$

After a few days of the inoculation of aeolosoma hemprichi, aeolosoma hemprichi starts to explosively propagate. In this study we measured the population density of aeolosoma hemprichi, inlet and outlet $\mathrm{COD}, \mathrm{NH}_{3}-\mathrm{N}$, and the removal rates of $\mathrm{COD}$ and $\mathrm{NH}_{3}-\mathrm{N}$. The initail concentrations of COD and $\mathrm{NH}_{3}-\mathrm{N}$ were $400-500 \mathrm{mg} / \mathrm{L}$ and $60-67$ $\mathrm{mg} / \mathrm{L}$. Fig. 2 shows the variation trends of $\mathrm{COD}$ and $\mathrm{NH}_{3}$ $\mathrm{N}$ in the reactor. After aeolosoma hemprichi is inoculated, the removal rate of COD remained stable in the reactor during the period of the explosive propagation of aeolosoma hemprichi. The average removal rate of COD was $90 \%$. On the $4^{\text {th }}$ and $10^{\text {th }}$ days, the removal rates of COD were respectively $82 \%$ and $84 \%$, due to the high COD of inlet water. The average removal rate of COD is less than $85 \%$. In addition, the removal rate of $\mathrm{NH}_{3}-\mathrm{N}$ in the reactor kept stable at around $95 \%$, and the average removal rate of $\mathrm{NH}_{3}-\mathrm{N}$ was about $95 \%$. On the $6^{\text {th }}$ day, the removal rate of $\mathrm{NH}_{3}-\mathrm{N}$ was less than $90 \%$. The result tells that the activated sludgebiofilm reactor is resistant to shock loads.

In the last five days, aeolosoma hemprichi starts to explosively propagate, but it doesn't impact the removal rates of $\mathrm{COD}$ and $\mathrm{NH}_{3}-\mathrm{N}$ (Fig. 3). Fig. 3 shows that the explosive propagation of aeolosoma hemprichi would not have an impact on the removal rate of COD and nitrification because the mineralization of aeolosoma hemprichi releases soluble COD, which is just suitable for being the
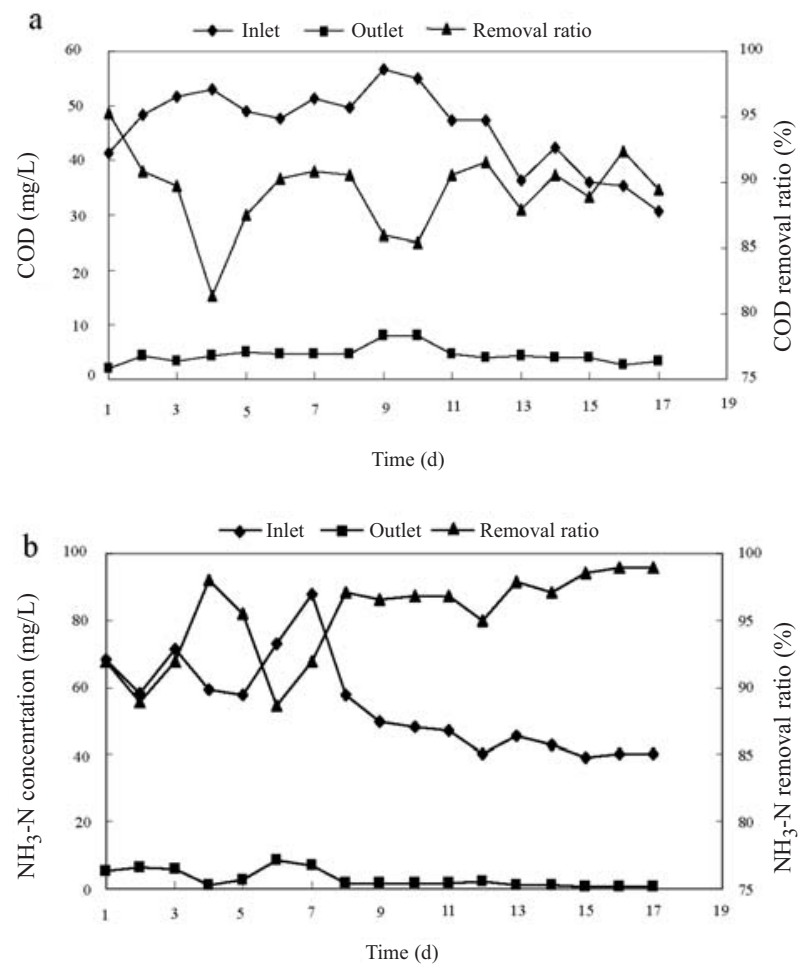

Fig. 2. The inlet and out trend of a) $\mathrm{COD}$ and b) $\mathrm{NH}_{3}-\mathrm{N}$ at $25^{\circ} \mathrm{C}$.

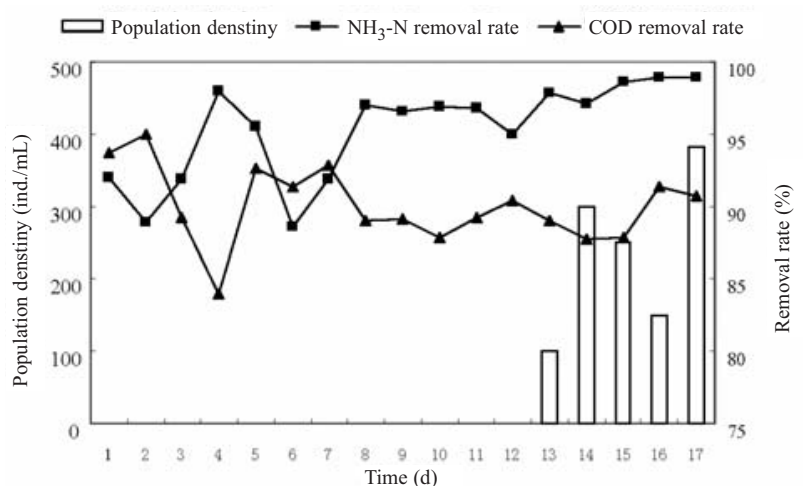

Fig. 3. The impact of the population density of aeolosoma hemprichi on the removal of COD and $\mathrm{NH}_{3}-\mathrm{N}$.

carbon source for the de-nitrification in the reactor. Wei et al. [28] stated that the explosive propagation of aeolosoma hemprichi in the reactor doesn't impact nitrifying bacteria. Further, they believed oligochaeta worms, such as aeolosoma hemprichi, do not selectively eat nitrifying bacteria. Their claims have also been verified in the activated sludgebiofilm reactor. Moreover, we measure the concentration of suspended solids (MLSS) and the amounts of biofilm before and after the explosive propagation of aeolosoma hemprichi. In addition, Wei et al. [28] tested the value of MLSS and biomass before and after the explosive propagation of aeolosoma hemprichi.

The results show that before and after the explosive propagation of aeolosoma hemprichi, the average concentrations of suspended solids (MLSS) in the reactor are $4,060 \mathrm{mg} / \mathrm{L}$ and 3,570 $\mathrm{mg} / \mathrm{L}$, respectively. This is because aeolosoma hemprichi eat suspended sludge. Therefore, the concentration of sludge remains within a relatively smaller range after the explosive propagation of aeolosoma hemprichi than that before the explosive propagation. The average amounts of biofilm on a filler unit before and after the explosive propagation of aeolosoma hemprich, are 15.0 $\mathrm{mg} / \mathrm{g}$ and $14.4 \mathrm{mg} / \mathrm{g}$, respectively. The difference is less than $1 \mathrm{mg} / \mathrm{g}$. That implies that aeolosoma hemprichi does not eat lots of biofilm when the explosive propagation of aeolosoma hemprichi occurs. In fact, aeolosoma hemprichi belongs to sequestered worms [29]; it would not be attached to the suspended filler and propagate. This fact is further certified through microscopic examination. Aeolosoma hemprichi is mostly living in suspended sludge, whereas there are many microbial species living in the biofilm, such as clock bug, rotatoria, etc. (Fig. 4).

\section{The Impact of the Explosive Propagration of Aeolosoma Hemprichi on the Release of TN} at $25^{\circ} \mathrm{C}$

Based on the above study, the explosive propagation of aeolosoma hemprichi doesn't have an impact on the removal rate of $\mathrm{COD}$ and $\mathrm{NH}_{3}-\mathrm{N}$. In the experiment we measure the concentrations of TN in inlet and outlet water within 5 days of aeolosoma hemprichi starting to explosively propagate. In the beginning, due to the excessive 
increase of influent load, the concentration of $\mathrm{NH}_{3}-\mathrm{N}$ is large in the reactor. In this case, the value of $\mathrm{pH}$ in the reactor ranges from 8 to 9 so that all of the aeolosoma hemprichi almost die. This is because the high concentration of $\mathrm{NH}_{3}-\mathrm{N}$ has toxic effects on aeolosoma hemprichi 16, and aeolosoma hemprichi are extremely sensitive to the non-ionic ammonia $\left(\mathrm{NH}_{3} \cdot \mathrm{H}_{2} \mathrm{O}\right)$. The high $\mathrm{pH}$ makes ammonia nitrogen increase, which is poisonous to the aeolosoma hemprichi. After the reactor stabilizes, we re-measure the value of TN in outlet and inlet water, and use them as total nitrogen before the explosive propagation of aeolosoma hemprichi. Fig. 4 presents the derived relationship between the explosive propagation of aeolosoma hemprichi and the value of TN in inlet and outlet water. The maximum population density of aeolosoma hemprichi is $383 \mathrm{ind} . / \mathrm{mL}$ (Fig. 4). When the population density of aeolosoma hemprichi reaches $66 \mathrm{ind} . / \mathrm{mL}$, it has a significant impact on the value of TN in inlet and outlet water in the reactor. And the releasing of nutrients cause the increase of the TN. The inlet TN change that much; at the same time, with the improving water load the concentration is also increased.

The Impact of the Explosive Propagation of Aeolosoma Hemprichi on the Removal Rates of COD, $\mathrm{NH}_{3}-\mathrm{N}$, and the Release Rate of TN at $20^{\circ} \mathrm{C}$

In the beaker experiment the ambient temperature is controlled to $20^{\circ} \mathrm{C}$ with a shaker. When water flows in or out of the reactor we measure $\mathrm{COD}, \mathrm{NH}_{3}-\mathrm{N}$, and TN in inlet and outlet water. After the reactor becomes stable, we start to inoculate aeolosoma hemprichi in order to determine whether the explosive propagation of aeolosoma hemprichi occurs. Fig. 5 depicts the associations among the population density of aeolosoma hemprichi and the removal rates of $\mathrm{COD}, \mathrm{NH}_{3}-\mathrm{N}$, and the release rate of $\mathrm{TN}$ in the reactor over the experimental time. As shown in Fig. 6a, the removal rate of ammonia nitrogen basically stabilized from $90 \%$ to $95 \%$ when the ambient temperature was below $20^{\circ} \mathrm{C}$. At the temperature of $25^{\circ} \mathrm{C}$, the removal rate of ammonia nitrogen stabilizes at above $95 \%$. That states that lowering temperature will inhibit nitrification. According to the removal rate of COD, when the ambient temperatures

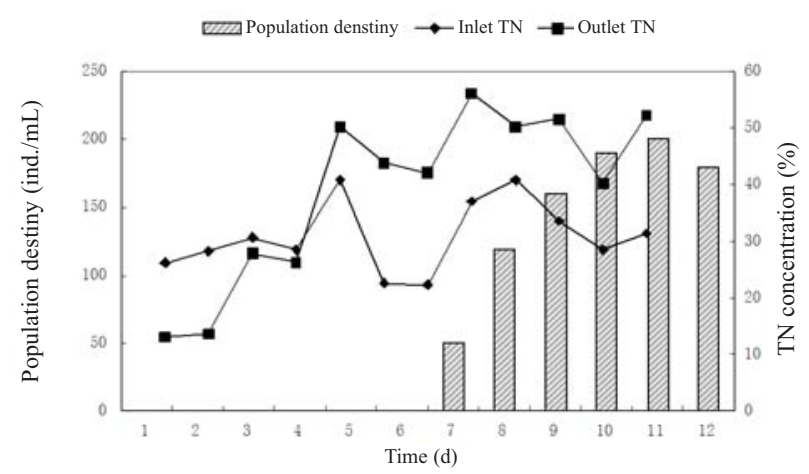

Fig. 4. The impact of population density of aeolosoma hemprichi on the value of TN.
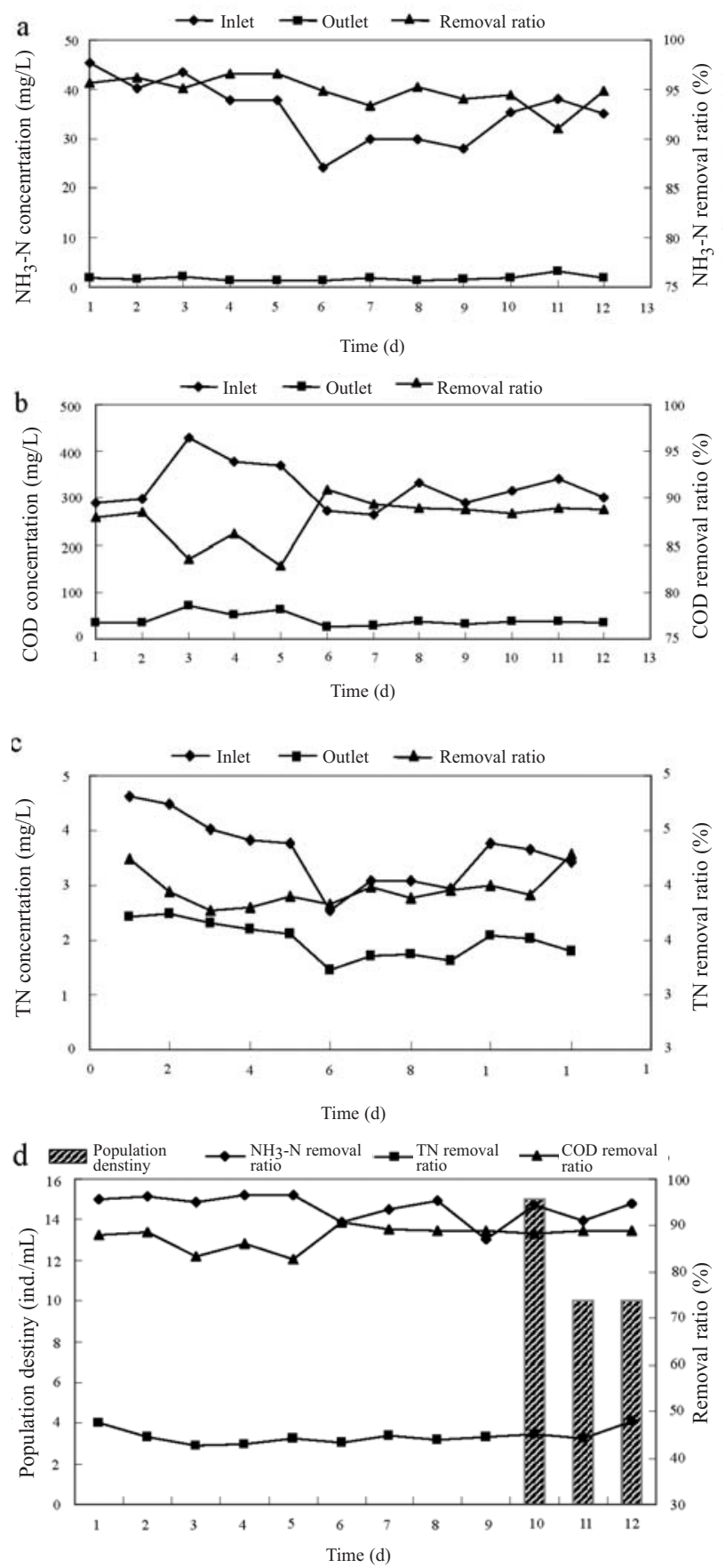

Fig. 5. The inlet and outlet a) $\mathrm{COD}, \mathrm{b}) \mathrm{NH}_{3}-\mathrm{N}$, c) $\mathrm{TN}$, and d) the population density of aeolosoma hemprichi at $20^{\circ} \mathrm{C}$.

are $20^{\circ} \mathrm{C}$ and $25^{\circ} \mathrm{C}$, and the filler dosing rate is $30 \%$, the average removal rate of COD are $88 \%$ and $90 \%$, respectively. Therefore, lowering temperature had little impact on the removal rates of COD (Fig. 5c). After the inoculation of aeolosoma hemprichi, the initial population density of aeolosoma hemprichi is $1 \mathrm{ind} . / \mathrm{mL}$. On the $10^{\text {th }}$ day the population density of aeolosoma hemprichi reached 15 ind./mL. After two days the population density of aeolosoma hemprichi remained at $10 \mathrm{ind} . / \mathrm{mL}$. But the removal rates of $\mathrm{COD}, \mathrm{NH}_{3}-\mathrm{N}$, and the release rate of $\mathrm{TN}$ in the reactor remained relatively stable. This indicates that the explosive propagation of aeolosoma hemprichi doesn't 
Table 1. Data sheet of various factors under different various temperature conditions.

\begin{tabular}{|c|c|c|c|c|}
\hline $\begin{array}{c}\text { Temperature } \\
\left({ }^{\circ} \mathrm{C}\right)\end{array}$ & $\begin{array}{c}\text { Maximum population } \\
\text { density (ind./mL) }\end{array}$ & $\begin{array}{c}\text { COD removal rate } \\
(\%)\end{array}$ & $\begin{array}{c}\mathrm{NH}_{3}-\mathrm{N} \text { removal rate } \\
(\%)\end{array}$ & $\mathrm{TN}_{\text {outlet }} / \mathrm{TN}_{\text {inlet }}$ \\
\hline 20 & 15.00 & 88 & 94 & 0.55 \\
\hline 25 & 383.33 & 90 & 95 & 4.20 \\
\hline 30 & 200.00 & 94 & 95 & 1.50 \\
\hline
\end{tabular}

occur. It doesn't lead to the deterioration of water quality when the population density of aeolosoma hemprichi is 15 ind./mL. So the temperature is not suitable for the growth of aeolosoma hemprichi.

\section{Impact of Explosive Propagation of Aeolosoma} Hemprichi on Removal Rates of COD, and $\mathrm{NH}_{3}-\mathrm{N}$, and the Release Rate of $\mathrm{TN}$ at $30^{\circ} \mathrm{C}$

In the beaker experiment the ambient temperature was controlled to $30^{\circ} \mathrm{C}$ with a shaker. When water flowed in or out of the reactor we measured $\mathrm{COD}, \mathrm{NH}_{3}-\mathrm{N}$, and $\mathrm{TN}$ in inlet and outlet water. After the reactor became stable we started to inoculate aeolosoma hemprichi. After a few days, when the initial population density of aeolosoma hemprichi reached 1 ind./mL, we frequently measured the population density of aeolosoma hemprichi every day so that we could determine whether aeolosoma hemprichi started to explosively propagate when the ambient temperature was $30^{\circ} \mathrm{C}$. Fig. 6 depicts the relationships between the population density of aeolosoma hemprichi and the removal rates of COD and $\mathrm{NH}_{3}-\mathrm{N}$, and the release rate of $\mathrm{TN}$ in inlet and outlet water.
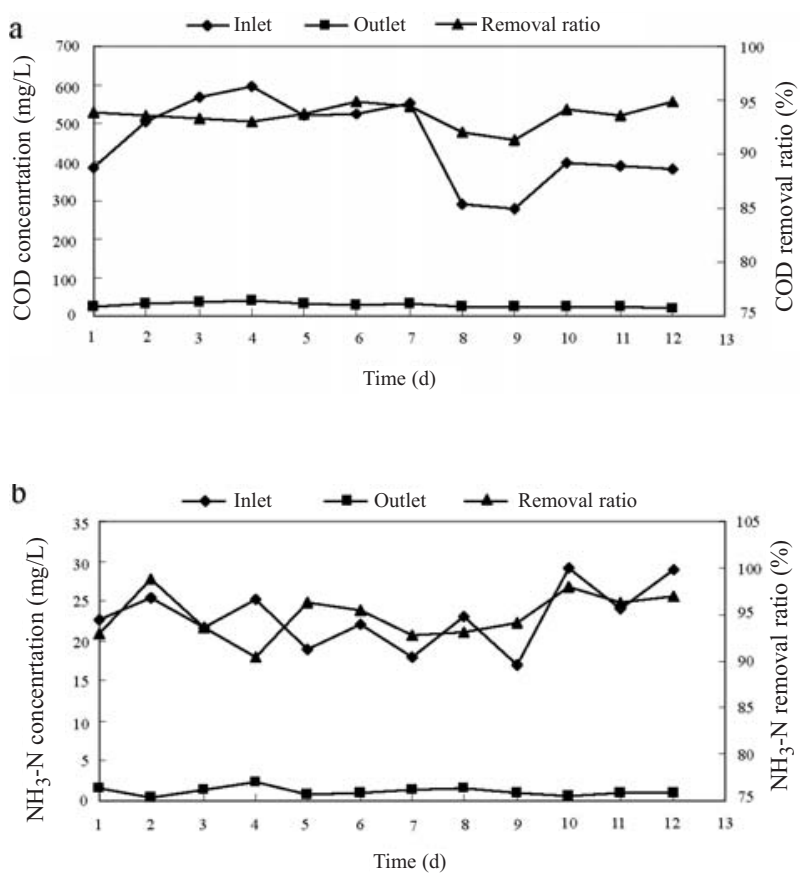

As shown in Fig. 6a, the removal rate of COD at $30^{\circ} \mathrm{C}$ is higher than those at $20^{\circ} \mathrm{C}$ and $25^{\circ} \mathrm{C}$. The average removal rate of COD reached $94 \%$ and the removal rate of outlet COD is kept below $50 \mathrm{mg} / \mathrm{L}$. The result explains that on the one hand, the activated sludge-biofilm reactor had highenough efficiency to remove $\mathrm{COD}$ at $30^{\circ} \mathrm{C}$. On the other hand, the result showed that the activity of the bacteria in both of the suspended and adhered sludge reached maximum at $30^{\circ} \mathrm{C}$. Fig. $6 \mathrm{~b}$ shows that at $30^{\circ} \mathrm{C}$ there was no obvious difference between the average removal rate of $\mathrm{NH}_{3}-\mathrm{N}$ at $25^{\circ} \mathrm{C}$ and $30^{\circ} \mathrm{C}$. Both were about $95 \%$. There occurred the explosive propagration of aeolosoma hemprichi in 7 days at $30^{\circ} \mathrm{C}$ after the inoculation of aeolosoma hemprichi in Fig. 6c. However, the explosive propagration of aeolosoma hemprichi didn't have significant impact on the removal rates of $\mathrm{COD}$ and $\mathrm{NH}_{3}-\mathrm{N}$, but it did on the value of total nitrogen (Fig. 6d). On the $7^{\text {th }}$ day the reactor started to release TN when the population density of aeolosoma hemprichi reached 50 ind./mL. In the sequent 6 days the population density of aeolosoma hemprichi continously grew. The maximum population density of aeolosoma hemprichi reached 200 ind./mL and was accompanied by the release of TN.

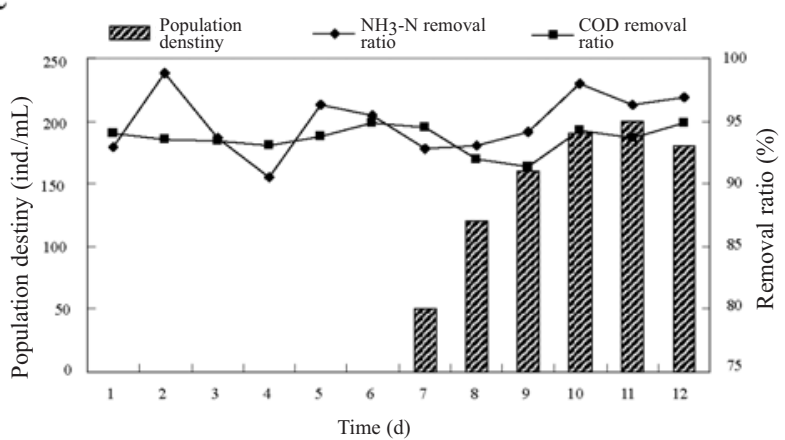

d

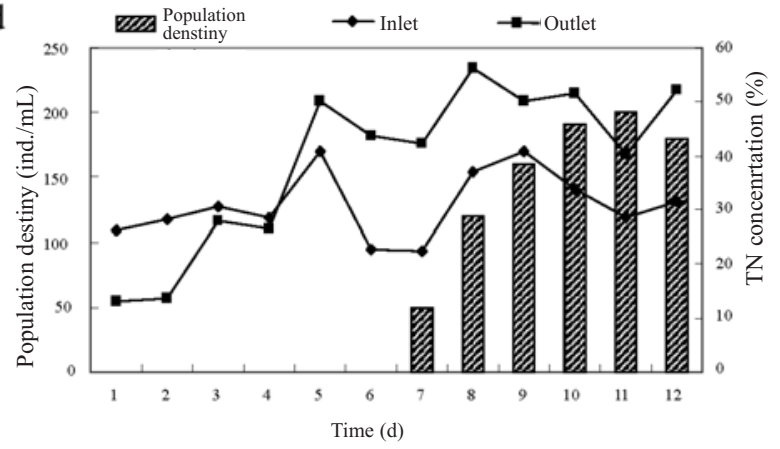

Fig. 6. The inlet and outlet a) nCOD, b) $\mathrm{NH}_{3}-\mathrm{N}$, c) TN, and d) the population density of aeolosoma hemprichi at $30^{\circ} \mathrm{C}$. 
Table 2. The correlation coefficient under various ambient temperatures.

\begin{tabular}{|c|c|c|c|c|c|c|}
\hline & & $\begin{array}{c}\text { Maximum } \\
\text { population } \\
\text { density }\end{array}$ & Temperature & $\begin{array}{l}\text { Removal } \\
\text { rate of COD }\end{array}$ & $\begin{array}{l}\text { Removal rate } \\
\text { of } \mathrm{NH}_{3}-\mathrm{N}\end{array}$ & $\begin{array}{c}\text { Total } \\
\text { nitrogen ratio }\end{array}$ \\
\hline \multirow{5}{*}{ Pearson } & Maximum population density & 1.000 & 0.502 & 0.330 & 0.867 & 0.994 \\
\hline & Temperature & 0.502 & 1.000 & 0.982 & 0.866 & 0.407 \\
\hline & Removal rate of COD & 0.330 & 0.982 & 1.000 & 0.756 & 0.227 \\
\hline & Removal rate of $\mathrm{NH}_{3}-\mathrm{N}$ & 0.867 & 0.866 & 0.756 & 1.000 & 0.809 \\
\hline & Total nitrogen ratio & 0.994 & 0.407 & 0.227 & 0.809 & 1.000 \\
\hline \multirow{5}{*}{ Sig. } & Maximum population density & . & 0.333 & 0.393 & 0.166 & 0.034 \\
\hline & Temperature & 0.333 & . & 0.061 & 0.167 & 0.366 \\
\hline & Removal rate of COD & 0.393 & 0.061 & . & 0.227 & 0.427 \\
\hline & Removal rate of $\mathrm{NH}_{3}-\mathrm{N}$ & 0.166 & 0.167 & 0.227 & . & 0.200 \\
\hline & Total nitrogen ratio & 0.034 & 0.366 & 0.427 & 0.200 & . \\
\hline \multirow{5}{*}{$\mathrm{N}$} & Maximum population density & 3 & 3 & 3 & 3 & 3 \\
\hline & Temperature & 3 & 3 & 3 & 3 & 3 \\
\hline & Removal rate of COD & 3 & 3 & 3 & 3 & 3 \\
\hline & Removal rate of $\mathrm{NH}_{3}-\mathrm{N}$ & 3 & 3 & 3 & 3 & 3 \\
\hline & Total nitrogen ratio & 3 & 3 & 3 & 3 & 3 \\
\hline
\end{tabular}

\section{Multivariate Regression Analysis under Various Temperatures}

We selected various ambient temperature conditions for inoculating aeolosoma hemprichi in the baker experiment. We found that varying degrees of explosive propagation of aeolosoma hemprichi occur when the ambient temperature reaches both $25^{\circ} \mathrm{C}$ and $30^{\circ} \mathrm{C}$. Table 1 presents the associate factors under various temperatures.

In the experiment we conduct multivariate regression analysis with SPSS19 and examine the correlation between the maximum population density of aeolosoma hemprichi and the ambient temperature, the correlation between the maximum population density of aeolosoma hemprichi and the removal rate of $\mathrm{COD}, \mathrm{NH}_{3}-\mathrm{N}$, and the release rate of TN (Table 2). In multivariate regression analysis, when the probability $\rho$ of the maximum value $F$ of the candidate variable is less than 0.10 , we introduce the candidate variable. When the probability $\rho$ of the minimum value $F$ of the candidate variable is more than 0.11 , we eliminate the candidate variable.

The correlation coefficient between the maximum population density of aeolosoma hemprichi and the release rate of TN is 0.994 in Table 2. The single significance test probability $\rho$ is 0.034 (less than 0.10 ). Therefore, there is a strong correlation between the maximum population density of aeolosoma hemprichi and the release rate of TN. The correlation coefficient between the ambient temperature and the removal rate of COD is 0.982 . The single significance test probability $\rho$ is 0.061 , (less than 0.10 ). This implies that there is a strong correlation between the ambi- ent temperature and the removal rate of COD. Multivariable correlation analysis with SPSS19 brought us to the conclusion that there is a strong correlation between the maximum population density of aeolosoma hemprichi and the release rate of TN, but there is no obvious correlation between the maximum population density of aeolosoma hemprichi and the removal rates of $\mathrm{NH}_{3}-\mathrm{N}$ and COD.

\section{Conclusions}

With the beaker experiment we study and simulate the activated sludge-biofilm reactor. In the study, we propose the impact indicators for analyzing the performance of an activated sludge-biofilm reactor during the period of the explosive propagation of aeolosoma hemprichi. On this basis, in the conditions of various temperatures, we observe factors and parameters affecting the operation of an activated sludge-biofilm reactor and examine how the population density of aeolosoma hemprichi affects the operation of the activated sludge-biofilm reactor. The experimental results show us:

(1) In the beaker experiment, when the rate of filler dosing is $30 \%$; the average removal rate of COD and the average removal rates of $\mathrm{NH}_{3}-\mathrm{N}$ are $90 \%$ and $95 \%$, respectively, the maximum population density of aeolosoma hemprichi is $383 \mathrm{ind} . / \mathrm{mL}$. When the population density of aeolosoma hemprichi is $66 \mathrm{ind} . / \mathrm{mL}$ in the reactor, the reactor starts to release $\mathrm{TN}$. Therefore we claim that aeolosoma hemprichi starts to explosively propagate when its population density reaches more than 66 
ind. $/ \mathrm{mL}$ and the ambient temperature is $25^{\circ} \mathrm{C}$. The reactor starts to release $\mathrm{TN}$ when the population density of aeolosoma hemprichi is 50 ind./mL and the ambient temperature is $30^{\circ} \mathrm{C}$, and $\mathrm{TN}$ is released. Therefore, we claim that aeolosoma hemprichi starts to explosively propagate when its population density reaches more than $50 \mathrm{ind} . / \mathrm{mL}$ and the ambient temperature is $30^{\circ} \mathrm{C}$.

(2) When aeolosoma hemprichi starts to explosively propagate, the activated sludge-biofilm reactor does not release $\mathrm{NH}_{3}-\mathrm{N}$ and COD. Aeolosoma hemprichi doesn't selectively eat ammonia-oxidizing bacteria. The existence of aeolosoma hemprichi doesn't have an impact on the removal rates of $\mathrm{NH}_{3}-\mathrm{N}$ and COD. However, the existence of Aeolosoma hemprichi does have a significant impact on the removal rate of total nitrogen. This conclusion has been verified by our subsequent experiments. Moreover, the amount of biofilm on the suspended filler does not significantly reduce before and after the explosive propagation of aeolosoma hemprichi. This result shows that aeolosoma hemprichi would not eat lots of biofilms.

(3) After conducting multivariable correlation analysis with SPSS19, we come to the following conclusion that there is a strong correlation between the maximum population density of aeolosoma hemprichi and the release rate of $\mathrm{TN}$, but there is no obvious correlation between the maximum population density of aeolosoma hemprichi and the removal rates of $\mathrm{NH}_{3}-\mathrm{N}$ and COD. Moreover, there is a strong correlation between ambient temperature and the removal rate of COD.

\section{Acknowledgements}

This work was financially supported by the National Natural Science Foundation of China (NSFC) (Grant No. 51008216; 51279108), the Leading Academic Discipline Project of Shanghai Municipal Education Commission (Grant No. J50502), the Major Project of Shanghai Municipal Science and Technology Commission (13DJ1400105), the Innovation Program of Shanghai Municipal Education Commission, China (12YZ100), and the special fund of State Key Joint Laboratory of Environment Simulation and Pollution Control (12K11ESPCT).

\section{References}

1. DI TRAPAN D., CHRISTENSSO M., ODEGAARD H. Hybrid Activated Sludge/Biofilm Process for the Treatment of Municipal Wastewater in a Cold Climate Region, a Case Study. Water Sci. Technol. 63, 1121, 2011.

2. DI TRAPANI D., CHRISTENSSON M., TORREGROSSA M., VIVIANI G., DEGAARD H. Performance of a hybrid activated sludge/biofilm process for wastewater treatment in a cold climate region: Influence of operating conditions. Biochem. Eng. J. 77, 214, 2013.

3. DE LUCA G., SACCHETTI R., LEONI E., ZANETTI F. Removal of indicator bacteriophages from municipal waste- water by a full-scale membrane bioreactor and a conventional activated sludge process: Implications to water reuse. J. Biores. Technol. 129, 1, 2013.

4. HASHIMOTO K., MATSUDA M., INOUE D., IKE M. Bacterial community dynamics in a full-scale municipal wastewater treatment plant employing conventional activated sludge process. J. Biosci. Bioeng. 118, 41, 2013.

5. SONG B.Y., CHEN X.F. Effect of Aeolosoma Hemprichi on Excess Activated Sludge Reduction. J. Hazard. Mater. 162, 300, 2009.

6. CONSTANTINE T.A., JOHNSON B. Innovative approaches for treatment of return liquors from anaerobic digestion. Proc. Water Environ. Feder. 608, 2006.

7. $\quad$ SHI J., XU F., WANG Z., STIVERSON J.A., YU Z., LI Y. Effects of microbial and non-microbial factors of liquid anaerobic digestion effluent as inoculum for solid-state anaerobic digestion of corn stover. J. Biores. Technol. 157, 188, 2014.

8. GUO W.Q., YANG S.S., XIANG W.S., WANG X.J., REN N.Q. Minimization of excess sludge production by in-situ activated sludge treatment processes - A comprehensive review. J. Biotechnol. Adv. 31, 1386, 2013.

9. WEI Y.S., VAN HOUTEN R.T., BORGER A.R., EIKELBOOM D.H., FAN Y.B. Minimization of excess sludge production for biological wastewater treatment. Water Res. 37, 4453, 2003.

10. ABE N., TANG Y.Q., MAKOTO I., SHIGERU M., KENJI $\mathrm{K}$. Pretreatment followed by anaerobic digestion of secondary sludge for reduction of sewage sludge volume. J. Water sci. and technol: a journal of the International Association on Water Pollution Research. 67, 11, 2013.

11. MAHMOOD T., ELLIOTT A. A review of secondary sludge reduction technologies for the pulp and paper industry. Water Res. 40, 2093, 2006.

12. BIYU S., XIAO F.C. Effect of Aeolosoma hemprichi on excess activated sludge reduction. J. Hazard. Mater. 162, 300, 2008.

13. PENG L., HUANG X., QIAN Y. Excess sludge reduction in activated sludge process through predation of aeolosoma hemprichi. Biochem. Eng. J. 28, 117, 2006.

14. GALILEE U.S., FAISAL I.H., HUU H.N., WENSHAN G., SHENG-JIE Y., WILLIAM E.P., LONG D.N. Sludge cycling between aerobic, anoxic and anaerobic regimes to reduce sludge production during wastewater treatment: Performance, mechanisms, and implications. J. Biores. Technol. 155, 395, 2014.

15. PEREZ-ELVIRA S.I., NIETO D.P., FDZ-POLANCO F. Sludge minimisation technologies. Rev. Environ. Sci. Biotechnol. 5, 375, 2006.

16. MERRYLIN J., KALIAPPAN S., ADISH KUMAR S., TAE YEOM I., RAJESH BANU J. Effect of extra polymeric substance removal on sludge reduction potential of B acillus licheniformis at its optimized $\mathrm{pH}$ condition. Water Environ. J. 281, 95, 2014.

17. RATSAK C.H., JAAP V. Sludge reduction by predatory activity of aquatic oligochaetes in wastewater treatment plants. science or fiction, A review. Aquat. Oligochaete. Biol. 4, 197, 2006.

18. HENDRICKX T.L., ELISSEN H.J., TEMMINK H., BUISMAN C.J. Operation of an aquatic worm reactor suitable for sludge reduction at large scale. Water Res. 45, 4923, 2011.

19. TIAN Y., LU Y.B. Simultaneous nitrification and denitrification process in a new Tubificidae-reactor for minimizing nutrient release during sludge reduction. Water Res. 44, 6031, 2010. 
20. SARIOGLU M., INSEL G., ARTAN N., ORHON D. Model evaluation of simultaneous nitrification and denitrification in a membrane bioreactor operated without an anoxic reactor. J. Membrane Sci. 33, 71, 2009.

21. XU Y., LIU J.M., WANG A.H., YU S. Study on Mechanism of Simultaneous Nitrification and Denitrification with Four Kinds of Fillers in Simulated Situ Bioremediation for Taihu Lake. J. Procedia Environ. Sci. 10, 2011.

22. WEI Y.S., FAN Y.B. Reducing Sludge Production by Predation and Its Factors Analysis in Conventional Activated Sludge Process. Environ. Sci. 26, 76, 2005.

23. LOU J.Q., SUN P.D., GUO M.X., WU G., WEI Y.S. Simultaneous sludge reduction and nutrient removal (SSRNR) with interaction between Tubificidae and microorganisms, A full-scale study. Bioresource. Technol. 102, 11132, 2011.

24. GHYOOT W., WILLY V. Reduced sludge production in a two-stage membrane-assisted bioreactor. Water Res. 34, $205,2000$.
25. WU P., JI X., SONG X., SHEN Y. Nutrient Removal from Municipal Wastewater and Microbial Community Analysis of a Combined ABR - MBR (CAMBR) Process. J. Clean Soil Air Water. 426, 2014.

26. WANG X.J., XIA S.Q., CHEN L., ZHAO J.F., RENAULT N.J., CHOVELON J.M. Nutrients removal from municipal wastewater by chemical precipitation in a moving bed biofilm reactor. Pro. Biochem. 41, 824, 2006.

27. ROSINDKA A., DABROWSKA L. Sewage sludge digestion at increased micropollutant content. J. Chemical Engineering Research and Design. 92, 51, 2013.

28. WEI Y.S., VAN HOUTEN R.T., BORGER A.R. Minimization of sludge production by Oligochaete in membrane bioreactor (MBR) and conventional activated sludge (CAS) processes. Acta Scientiae Circumstantiae. 24, 405, 2004.

29. ZHU H., WEI Y.S., YANG Y. Factors affecting sludge volume reduction induced by Tubificidae. Acta Scientiae Circumstantiae. 28, 1141, 2008. 